\title{
A SEMÂNTICA DO TRABALHO DE CATAÇÃO E DOS RESÍDUOS SÓLIDOS (LIXO): O OLHAR DE ESTUDANTES DA ESCOLA MUNICIPAL ÁLVARO BOTELHO - LAVRAS/MG
}

\author{
Luiz Augusto Bronzatto ${ }^{1}$ \\ Lucas Canestri de Oliveira ${ }^{2}$
}

Resumo: A partir da Lei $n^{-}$12.305/2010, que institui a Política Nacional de Resíduos Sólidos, novas formas discursivas são visualizadas no que tange aos resíduos e a atividade do catador de material reciclável, denominadas de discurso normativo. Este discurso será validado caso os aspectos correlacionados à semântica do "lixo" e do trabalho do catador transpor para uma abordagem positiva. Assim, este trabalho busca refletir sobre 0 desenvolvimento do discurso normativo da gestão dos resíduos sólidos junto a estudantes da Escola Municipal Álvaro Botelho, localizada em Lavras/MG. Além disso, busca trazer subsídios ao projeto de extensão universitária denominado "Do coletar ao reciclar". Os resultados apontam a incorporação do discurso normativo pela maioria dos estudantes, analiticamente diferenciados em críticos e ingênuos.

Palavras-chave: Catador; Materiais Recicláveis; Lixo; Discurso e Semântica.

${ }_{1}^{1}$ Universidade Federal de Lavras. E-mail: gutobronzatto@gmail.com

${ }^{2}$ Universidade Federal de Lavras. E-mail: canestri@gmail.com 


\section{Introdução}

O presente artigo tem a intenção de avaliar e refletir sobre o desenvolvimento do discurso normativo da gestão dos resíduos sólidos urbanos, incluindo neste âmbito a figura do trabalho do catador e a leitura sobre os materiais recicláveis, junto a estudantes do $6^{\circ}$ e $7^{\circ}$ ano da Escola Municipal Álvaro Botelho, em Lavras/MG. A partir desse esforço pretende-se ainda trazer subsídios para o projeto de extensão universitária, denominado "Do coletar ao reciclar", coordenado pela Incubadora Tecnológica de Cooperativas Populares/ITCP da Universidade Federal de Lavras (UFLA), pois neste ano dará início uma nova etapa de seu cronograma, incluindo recémchegados bolsistas inseridos no sistema municipal de educação.

O entendimento sobre discurso normativo da gestão dos resíduos sólidos neste trabalho parte de aspectos relacionados ao tema desenvolvidos antes e após a criação da Política Nacional de Resíduos Sólidos, pois a partir desta estabeleceu-se um marco legal no setor orientando determinadas ações de gestão dos resíduos sólidos no sentido de estimular um sistema produtivo com prudência ecológica, eficiência econômica e equidade social.

Neste sentido, serão apresentados, de forma breve, os aspectos históricos sobre o tema e como se deu o avanço do termo lixo ao resíduo, bem como a semântica que gira entorno do catador e do material reciclável, a fim de alicerçar a necessidade de resignificar as compreensões sobre o lixo e, por consequência, sobre o catador, para que a atividade seja valorizada no âmbito social. Estes temas são tratados no segundo tópico deste artigo. O enfoque analítico utilizado, exposto no terceiro tópico, engloba questões correlatas à abordagem discursiva, considerando a Análise Crítica do Discurso, a fim de compreender os aspectos que envolvem a construção de discursos, positivos e negativos, sobre o lixo e o catador de materiais recicláveis. Esta construção, por sua vez, deverá alicerçar o modelo de análise proposto, que parte da consorciação do modelo construcionista (SPINK, 2004) e do modelo da "construção do conceito" (QUIVY; CAMPENHAUDT, 1992). O quarto tópico narra sobre o método utilizado, cujo instrumento de pesquisa se configurou num questionário fechado com algumas escalas do tipo Likert. As respostas originárias de duas questões específicas do questionário subsidiaram a construção de um índice semântico, envolvendo aspectos relacionados ao trabalho do catador e ao material reciclável. Este índice e as demais variáveis utilizadas configuram-se a base para o tratamento dos dados, realizados por meio do software SPSS (versão 17.0) (apresentado no quinto tópico), tendo por base a análise de cluster e análise discriminante.

As conclusões deste trabalho estão expostas no sexto e derradeiro tópico, onde se pôde depreender que há um discurso normativo estabelecido pela maioria dos estudantes abordados, embora analiticamente separados em críticos e ingênuos. 


\title{
O Problema em análise: breve contexto
}

Os resíduos sólidos, cotidianamente chamados de lixo, vêm progressivamente tornando-se um dos maiores problemas na atualidade, sendo que sua solução perpassa pelo esclarecimento do maior número possível de pessoas (OLIVEIRA, 2010). A promulgação da Lei Federal $\mathrm{n}^{\circ}$ 12.305, de 02 de agosto de 2010, que institui a Política Nacional de Resíduos Sólidos, representa um avanço no trato da questão, pois, apresenta instrumentos de gestão fundamentais para a operacionalização técnica da Política, tais como: ferramentas como a logística reversa, o papel dos conselhos de meio ambiente e das associações e cooperativas de catadores, além de instrumentos econômicos e financeiros que garantem a aplicação de suas diretrizes. De acordo com o marco legal, os resíduos sólidos são diferenciados em: i) Urbanos, ii) Industriais, iii) Rurais, iv) Hospitalares e v) Especiais. No dia a dia, o resíduo sólido que geramos corresponde ao resíduo urbano que, por sua vez, são subdivididos em dois tipos: Reversos e Rejeitos (BRASIL, 2010).

Do ponto de vista econômico, a gestão dos resíduos sólidos é composta por todas as etapas de um sistema produtivo que visa à reutilização, o reaproveitamento, a reciclagem, a compostagem e a geração de energia, de tal modo que a otimização da logística reversa configura-se o início desse sistema (OLIVEIRA, 2010).

A literatura aponta que historicamente atribuem-se sentidos negativos ao trabalho com resíduos, bem como aos próprios resíduos em si. Essa semântica negativa atrapalha o desenvolvimento do sistema produtivo como um todo, perseverando um manejo imprudente do ponto de vista ambiental, ineficaz economicamente e socialmente excludente. Estas concepções surgem através dos discursos coletivos (FOSSÁ, 2006).

Carmo (2009) versa que tanto o lixo quanto o trabalho de catação vêm passando por uma ressignificação, onde o primeiro, de uma questão meramente sanitária, passou a entrar na pauta ambiental e econômica, e o trabalho de catação progressivamente galga degraus no sentido de seu reconhecimento como profissão. De acordo com a autora supracitada:

\begin{abstract}
A conotação que se passa a dar aos resíduos, à medida que passam a ser considerados como reciclável, decorre, principalmente, do papel desempenhado por setores sociais imbuídos de um discurso ambientalista ou econômico devido aos problemas por ele provocados ou pelas soluções que ele passa a representar para a economia dos recursos escassos. Este novo olhar permite que se fale em ressemantização do lixo pós-consumo que, a 'grosso modo', significa, atribuir um caráter de utilidade ao que antes era inútil, como algo que pode retornar ao ciclo produtivo como matéria-prima para a fabricação de outros produtos (CARMO, 2009, p.2).
\end{abstract}

Revbea, São Paulo, V.9, № 2: 270-286, 2014. 
A partir de tais argumentos constata-se que o significado social do lixo afeta a forma como os sujeitos relacionam-se economicamente com ele, impedindo os catadores de se beneficiarem como poderiam das oportunidades econômicas desse sistema produtivo (CARMO; OLIVEIRA; ARRUDA, 2006). Para que a sociedade perceba o catador como um trabalhador digno é necessário associar o trabalho de catação a significados sociais positivos, assim como para potencializar o sistema produtivo dos resíduos sólidos urbanos se faz necessário melhorar as condições de trabalho do catador (CARMO, 2005). Nessa equação, há dois elementos fundamentais: i) o reconhecimento simbólico e a valorização da atividade de catador a partir da adoção de novos significados para esta tarefa, e ii) a institucionalização progressiva de um discurso positivo sobre o lixo, a fim de contribuir com uma ação coletiva (separação dos resíduos) que colabore com a logística reversa.

Em Carmo (2009) argumenta-se que o lixo é historicamente definido como qualquer objeto sem valor ou utilidade; detrito oriundo de trabalhos domésticos, industriais etc. que se joga fora. O termo "lixo" passa a ser denominado "resíduo" a partir do século XX, em função do material que começa a ser descartado após o advento da sociedade de consumo. Embora lixo e resíduo sejam usados cotidianamente como sinônimos, este último estaria associado ao material sólido classificável, aproveitável, reutilizável, reciclável, etc., em oposição ao rejeito, que se refere ao que não pode ser aproveitado. Destarte, o lixo seria portador de um simbolismo que, devido à decomposição e ao odor, geram não só repugnância, mas também a associação com aquilo que é rejeitado e inútil, com o caos, a desordem e a morte.

No Brasil a atividade de catador de material reciclável, apesar de existir há mais de 50 anos, somente a partir da década de 1990 ganhou destaque. Embora realizada desde os primórdios de modo informal, recentemente os catadores deram início a processos organizativos por meio da formação de cooperativas e de formas de luta diversas para o reconhecimento desta atividade como profissão (CARMO; OLIVEIRA; MIGUELES, 2004). Por meio de tal processo organizativo, tem-se uma oportunidade de buscar maior valorização social, incluindo a imagem social do próprio catador, superando, inclusive, uma autodeterminação depreciativa, pois de acordo com os princípios do construcionismo, as representações individuais construídas pelos catadores a partir do seu trabalho aparecem nitidamente como um reflexo do conceito que a sociedade constrói sobre eles. Ou seja, as concepções que eles possuem de si próprios surgem a partir do discurso da sociedade.

Fossá (2006) argumenta que o não conhecimento do significado do próprio trabalho do catador, bem como o não reconhecimento da importância do mesmo para a sociedade, produz a visão de um trabalho desinteressante atrelado a uma baixa autoestima. Portanto, o entendimento desta relação é fundamental para que se perceba, inclusive, como o significado social do lixo pode afetar os processos de formação da identidade e a motivação dos sujeitos para lidarem com ele. 
A partir dessa abordagem, buscou-se identificar junto aos estudantes do 6ำ e $7^{\circ}$ ano da Escola Municipal Álvaro Botelho, a percepção sobre o trabalho do catador, bem como sobre os resíduos sólidos, a partir da semântica negativa e positiva que os alunos possuem em relação a tais temas. Desta forma, os resultados desse trabalho visam, também, subsidiar as ações de extensão universitária nessa escola no que tange a educação ambiental por meio de ações de reaproveitamento de rejeitos.

\section{O enfoque analítico}

As técnicas de análise utilizadas por diferentes pesquisadores para identificar as características linguísticas relevantes de um discurso social são muito amplas e qualquer recém-chegado a este estudo ficará confuso pela variedade de abordagens analíticas existentes (STUBBE et al., 2003). Algumas dessas técnicas focalizam o nível das macro-estratégias discursivas, examinando, por exemplo, os padrões retóricos, enquanto que outras adotam uma abordagem mais gramatical, explorando dessa forma os detalhes relevantes de sintaxe e das organizações semânticas (STUBBE et. al., 2003). Sob a perspectiva das estratégias discursivas, Phillips, Sewell, e Jaynes (2008) apresentam uma das diferentes formas de análise do discurso: a Análise Crítica do Discurso. Essa técnica foi desenvolvida por Normam Fairclough e seus colegas a partir de 1992 como uma resposta às abordagens analíticas que antes tinham um foco muito estreito sobre os aspectos micro linguísticos do discurso, negligenciando assim seus aspectos macro sociais. Para estabelecer uma ligação metodológica entre a escala micro, de uso da linguagem cotidiana, e a escala macro, da estrutura social, este enfoque trata de usar a linguagem tanto como um objeto quanto como uma prática social.

Para Stubbe et. al. (2003), a análise crítica do discurso, diferentemente de outras abordagens, exige do analista a investigação da gama mais evidente do discurso para identificar padrões macro-discursivo. E embora isto não exclua uma análise detalhada de pequenos trechos, em geral, esta abordagen requer uma transcrição muito menos detalhada dos dados do ponto de vista gramatical. Existe um número crescente de pesquisadores que conceituam as sociedades, as instituições e as identidades individuais como discursivamente construídas (PHILLIPS et. al., 2008). Destaca-se que a análise crítica do discurso é uma dessas ferramentas que possibilitam a investigação deste processo visto que:

A análise crítica do discurso tem como objetivo revelar as ligações entre o poder, à linguagem e a ideologia, e os analistas críticos do discurso tem o objetivo de descrever como o poder e a dominação são produzidos e reproduzidos na prática social através do discurso e de estruturas de interações institucionalizadas (STUBBE et. al., 2003, p.367). 
De acordo com Phillips et. al. (2008), todos os indivíduos produzem "textos", isto é, envolvem-se nas práticas discursivas do cotidiano tendo assim possibilidade de moldar conceitos, objetos e posições de sujeito. Considerando o discurso como a conexão entre os textos e o contexto social tem-se um quadro para a consideração de como a produção de conjuntos de textos leva à mudança ou estabilidade no contexto social e vice-versa. Dessa forma, a análise crítica do discurso oferece uma abordagem para explorar os processos de formação discursiva e a construção social da qual emanam macrofenômenos sociais e atos de sentido individual (PHILLIPS et. al., 2008).

\section{Aspectos do discurso negativo}

A semântica negativa é compreendida por meio dos significados pejorativos atribuídos ao lixo e que por essa razão remetem os trabalhos voltados para o seu manuseio à ideia de degradação social (CARMO, OLIVEIRA \& ARRUDA, 2006). Carmo (2005), a partir de um trabalho realizado com catadores de material do Rio de Janeiro, aponta o papel exercido pela semântica negativa do lixo na atividade de catação, ao ponto de interferir no processo de construção de identidade profissional do catador, na formação de redes de contato e cooperação e na organização econômica e eficiência do trabalho. Estas questões aproximam-se das análises de Fossa (2006).

... as concepções dos catadores representam uma dialética entre o que eles pensam sobre si e o que eles pensam que a sociedade pensa sobre eles, e nessa 'colcha de retalhos' vai se formando as representações coletivas. De modo que estes dois discursos estão, de um modo ou de outro, internalizados tanto nos catadores quanto nos demais membros da sociedade (FOSSA, 2006, p.10).

O significado do lixo pode remeter a ideias como degeneração, decomposição, resto, como objeto sem valor ou utilidade. Tal fato pode levar a associação com coisa ordinária ou fora do lugar, caos e bagunça e, por suas características desagradáveis e incômodas (odor, aparência, decomposição) é que advêm significados como morte, limite e fim. Estaria aqui a principal razão de o lixo ser tratado como tabu (CARMO; OLIVEIRA; ARRUDA, 2006). Considerado como aquilo que perdeu a utilidade ou valor e que por esse motivo é descartado pela sociedade, os resíduos estão impregnados de uma conotação negativa. Os catadores sofrem impacto desse aspecto cultural negativo relacionado ao lixo em função de trabalharem diretamente no seu manuseio (CARMO, 2005). 


\section{Aspectos do discurso positivo}

O homem moderno, querendo ou não, busca em todas suas interações com a realidade encontrar seu lugar na sociedade. Os catadores encontram na realização de um trabalho que devolve o lixo ao ciclo natural da vida (FOSSÁ, 2006). Quando o lixo começa a ser tratado como algo de valor pelos diversos atores sociais, seu significado é alterado por uma semântica positiva e isso se reflete no sistema produtivo. A semântica positiva, seja do trabalho de catador ou do material, tem como seus principais vetores o discurso socioambiental e socioeconômico (CARMO, 2005). O discurso socioambiental compreende que a otimização do sistema produtivo da reciclagem apresenta medidas reais para a solução de problemas contemporâneos (FOSSÁ, 2006). Esse discurso é corroborado, inclusive, por indicadores sobre a reciclagem, como por exemplo, da UNICEF (2000) que aponta o Brasil como um dos mais bem conceituados países no tocante a reciclagem, sendo responsável pelo gerenciamento de cerca de $90 \%$ dos materiais que alimentam as indústrias nacionais de reciclagem (CARMO, 2005).

Um trabalho sem reconhecimento coletivo pode afetar a autoestima e a identidade profissional, pois sem a autoestima o sujeito fica impossibilitado de construir confiança nas suas capacidades, reconhecê-las ou identificá-las em si próprio. Não as reconhecendo em si fica também impossibilitado de reconhecêlas no outro, logo, de estabelecer relações de confiança mútua, de cooperação e de reciprocidade (CARMO; OLIVEIRA; ARRUDA, 2006). Outros aspectos positivos citados com frequência entre os catadores, segundo Fossá (2006), são a possibilidade de gerenciar o tempo de trabalho, trabalhar entre amigos, além dos aspectos de utilidade e honestidade.

\section{O modelo de análise}

O modelo de análise proposto parte da consorciação do modelo construcionista (SPINK; FREZZA. 2004) e do modelo "construção do conceito" (QUIVY; CAMPENHAUDT, 1992), sendo ambos abaixo descritos.

\section{a) $\mathrm{O}$ modelo construcionista}

Para o construcionismo a linguagem também é concebida como uma coisa e como uma ação social. Deste modo o enfoque busca entender tanto as práticas quanto os repertórios das produções discursivas. Sua abordagem teórico-metodológica trabalha com a interface dos aspectos de três dimensões básicas: (i) os aspectos linguísticos; (ii) os aspectos da pessoa e (iii) os aspectos históricos (SPINK; FREZZA, 2004). Para esse modelo de análise, a realidade não existe independente de nosso modo de acessá-la, ou seja, só apreendemos os objetos que se nos apresentam a partir de nossas categorias, convenções, práticas, linguagem, enfim, dos processos de objetivação (SPINK; MEDRADO, 2004).

Estes processos são os objetos de análise do construcionismo, o sentido é uma construção social historicamente datada e culturalmente localizada; 
destarte, dar sentido ao mundo é uma força poderosa e inevitável na vida em sociedade, além de não ser um fenômeno intra-individual e sim sociolinguístico (SPINK; LIMA, 2004).

Pesquisas dessa natureza, argumenta Spink e Medrado (2004), tem como objetivo apresentar estratégias para dar visibilidade ao processo de interpretação, partindo do pressuposto de que fazer ciência é uma prática social e seu sucesso e legitimação estão associados: à possibilidade de comunicação de seus resultados; à problematização das evidências; e na abordagem sobre a natureza do processo de interpretação.

\section{b) $O$ modelo Construção do Conceito}

A partir do "Manual de Investigação em Ciências Sociais" (QUIV; CAMPENHAUDT, 1992), aprofundou-se sobre a teorização conceitual ou como chamada pelos autores, "construção do conceito", sendo este defendido como uma construção metodológica de investigação em ciências sociais que dá base para toda e qualquer investigação, pois é subjetiva e inacabada, embora testada, refutada ou corroborada. A conceitualizacão é uma construção abstrata, detecta as dimensões que são subdivididas em componentes que, por sua vez, são medidas por meio de indicadores visando exprimir o essencial da realidade. Um indicador pode ser apenas uma marca, um sinal, uma palavra, uma expressão, uma opinião ou qualquer fenômeno que nos informe acerca do objeto da nossa construção. Seu objetivo é nos conduzir ao real e confrontarmos com ele. Muitas vezes, em ciências sociais, os conceitos e suas dimensões não são expressos em termos diretamente observáveis, mas nesse trabalho de investigação, a construção não é pura especulação, pois os procedimentos norteiam-se por um enfoque analítico (QUIVY; CAMPENHAUDT, 1992).

No presente trabalho o conceito chave a ser analisado será a Gestão dos Resíduos Sólidos, sendo este dividido em duas grandes dimensões que levaram em consideração a existência do agente humano e dos recursos disponíveis, quais sejam: i) Trabalho e ii) Material. Cada dimensão deriva em três componentes que, considerando o modelo construcionista, são: (a) os aspectos linguísticos, (b) os aspectos da pessoa e (c) os aspectos históricos (de forma sucinta, relatado nos tópicos anteriores). Por fim, estes componentes deverão ser "revelados" a partir de indicadores sustentados pela literatura que debate o tema. O quadro 1 demonstra a ideia que se aplica a esse trabalho.

Estas argumentações teóricas, bem como o breve contexto sobre o problema narrado anteriormente, configuraram-se a base para 0 estabelecimento do método proposto e das análises estabelecidas, tendo em vista o alcance do objeto central desse trabalho. 
Quadro 1: Os Modelos Consorciados

\begin{tabular}{|c|c|c|c|}
\hline Conceito & Dimensões & Componentes & Indicadores \\
\hline \multirow[t]{2}{*}{$\begin{array}{l}\text { Gestão dos } \\
\text { Resíduos } \\
\text { Sólidos }\end{array}$} & Trabalho & $\begin{array}{l}\text { Linguísticos } \\
\text { Da pessoa } \\
\text { Históricos }\end{array}$ & $\begin{array}{l}\text { Seis questões relacionadas } \\
\text { aos aspectos semânticos } \\
\text { positivos e negativos }\end{array}$ \\
\hline & Material & $\begin{array}{l}\text { Linguísticos } \\
\text { Da pessoa } \\
\text { Históricos }\end{array}$ & $\begin{array}{l}\text { Seis questões relacionadas } \\
\text { aos aspectos semânticos } \\
\text { positivos e negativos }\end{array}$ \\
\hline
\end{tabular}

\section{Método}

O instrumento utilizado para a pesquisa foi um questionário com perguntas fechadas, composto por 12 questões, sendo 5 do tipo Likert. A elaboração do questionário buscou contemplar linguagem de fácil entendimento, adaptada para o público em questão (estudantes do $6^{\circ}$ e $7^{\circ}$ ano do ensino fundamental). As questões consideraram de forma paritária aspectos relacionados ao catador e ao material reciclável, de modo que o tratamento dos dados coletados levasse a resultados cuja interpretação perpassaria pela compreensão do público pesquisado sobre a semântica (positiva e negativa) relacionada ao trabalho do catador e ao material reciclável.

Os questionários foram aplicados tendo por referência a população finita dos estudantes do $6^{\circ}$ e $7^{\circ}$ ano do ensino fundamental da Escola Municipal Álvaro Botelho, composta por 203 alunos. Buscando-se obter 95\% de limite de confiança e uma margem de erro de $5 \%$, aplicou-se a seguinte fórmula a fim de calcular o número mínimo de questionários necessários: $n=Z^{2} \times P \times Q \times N / e^{2} \times$ $(N-1)+Z^{2} \times(P \times Q)$, resultando em 133 questionários. Neste trabalho foram aplicados 147 questionários, sendo 3 descartados pelo fato da ocorrência de missing. Portanto, as análises deste trabalho consideraram 144 questionários válidos, sendo tal amostragem estatisticamente significativa. As duas primeiras questões do questionário foram estabelecidas a partir da revisão do tema resíduos sólidos, bem como considerando dos debates com o coletivo envolvido na execução do projeto de extensão universitária, onde se estruturou uma seleção de palavras que remetesse a um dos quatro grupos analíticos estabelecidos, denominados pelos autores de grupos semânticos. São eles: i) Semântica Positiva do Trabalho (SPT), ii) Semântica Negativa do Trabalho (SNT), iii) Semântica Positiva do Material (SPM), e iv) Semântica Negativa do Material (SNM). O Quadro 2 apresenta o conjunto de palavras utilizadas em cada grupo semântico. 
Quadro 2: Grupo semântico e palavras chave associadas

\begin{tabular}{|c|c|}
\hline Semântica positiva do trabalho & Semântica negativa do trabalho \\
\hline Dinheiro & Perigoso \\
Profissicional & Vergonha \\
Importante & Fracasso \\
Honesto & Pobreza \\
Útil & Ruim \\
\hline Semântica positiva do material & Semântica negativa do material \\
\hline Reciclável & Sujo \\
Reaproveitável & Nojento \\
Útil & Lixo \\
Matéria-prima & Fedor \\
Resíduo & Perigoso \\
\hline
\end{tabular}

Estas palavras ficaram dispostas de forma aleatória nas questões 1 e 2 do questionário e cada estudante foi orientado a marcar exatamente 5 palavras. Desta forma, se um estudante marcou 3 palavras do grupo relacionado à semântica positiva do trabalho, necessariamente houve 2 palavras do grupo relacionado à semântica negativa. Os indicadores são correlacionados em "cargas numéricas" que no exemplo em questão são (+3) e (-2) e logo em seguida somados. O Resultado Semântico do Trabalho (RST) foi, portanto, de valor (+1). O mesmo procedimento foi realizado com a Dimensão Material que apresentará ao final o Resultado Semântico do Material (RSM). Após esse primeiro tratamento, partiu-se para a soma dos Resultados Semânticos (RS), considerando: RST+RSM. Para cada Resultado Semântico possível (11 no total) foi atribuído um Valor de Referência variando de 0 a 10. Finalmente, estes valores de referência são convertidos para um índice de 0 a 1 por meio de uma simples regra de três.

O resultado do índice semântico, assim como as outras 10 variáveis utilizadas no questionário, foi submetido à análise de cluster e análise discriminante. Para isso, utilizou-se o software SPSS (versão 17.0). Malhotra (2006) narra que a análise de cluster configura-se uma técnica usada para classificar objetos ou casos em grupos relativamente homogêneos, também denominados conglomerados. Os objetos em cada conglomerado tendem a ser semelhantes entre si, mas diferentes de objetos em outros conglomerados. No presente trabalho adotou-se o procedimento hierárquico de aglomeração, empregando o método de Ward e a medida de similaridade distância euclidiana ao quadrado, sendo, por fim, extraídos dois agrupamentos. Já as técnicas de análise discriminante, de acordo com Aaker, Kumar e Day (2001), são utilizadas para classificar indivíduos em um, dois ou mais grupos alternativos (ou populações), como base de um conjunto de mensurações. As populações são distintas, onde cada indivíduo pertence a uma delas. Essas técnicas 
também podem ser utilizadas para identificar quais variáveis contribuem para que se faça tal classificação.

\section{Descrição dos resultados a partir da análise de cluster e discriminante}

Ao ser executado a análise de cluster no conjunto de questionários, foi gerado um modelo com 2 e 3 clusters. Porém, optou-se por trabalhar com o modelo que ofereceu a saída de dois clusters, pois: i) no modelo de 3 clusters, um dos agrupamentos foi integralmente absorvido no modelo de 2 clusters, o que levou a inferir que tais agrupamentos possuíam características semelhantes; e ii) ao utilizar como modelo de análise uma construção teórica que argumenta sobre a coexistência de dois discursos relacionados a semânticas opostas (chamadas de positivas e negativas, atribuídas ao trabalho com os resíduos sólidos, bem como ao próprio resíduo), visualizou-se que dois agrupamentos seriam mais adequados ao supracitado modelo, tendo em vista o objetivo de identificar na amostra a coexistência de tais discursos.

Da amostra de 144 questionários válidos, 39 casos formam o cluster (1) e 105 o cluster (2). É importante ressaltar que dentre as variáveis analisadas, três são descritivas: sexo, ano escolar e idade. Os resultados gerados apontaram que no cluster (1) existe uma maioria de meninos $(28,1 \%$ a mais que meninas), ao passo que no cluster (2) a diferença de gênero é de apenas $1 \%$, pendendo para as meninas. Em relação ao ano escolar, os clusters também possuem características distintas, pois do total de estudantes do $7^{\circ}$ ano, a maioria, correspondendo a $85,9 \%$ dos casos, encontra-se no cluster (2) e somente $14,1 \%$ dos casos no cluster (1), configurando uma diferença de $71,8 \%$. Em relação aos estudantes de $6^{\circ}$ ano percebe-se uma maior aproximação, onde $57,6 \%$ dos casos encontram-se no cluster (2) e $42,4 \%$ no cluster (1), configurando uma diferença de 15,2\%. Embora a variável ano escolar indique uma diferença entre os clusters, a mesma não acontece com a variável idade, cujas médias entre os clusters (1) e (2) são virtualmente idênticas 12,49 e 12,50 anos, respectivamente.

Ao se comparar as médias das 11 variáveis utilizadas em relação aos clusters, pôde-se observar que o cluster (1) possui quatro médias superiores ao cluster (2), e este possui sete médias superiores ao cluster (1). Este fato indica que o cluster 2 mais se aproxima ao que se definiu no modelo de análise como sendo semântica positiva, embora não se pode descartar que o cluster (1) também aponte para tal semântica, pois, com exceção de uma média relacionada ao cluster (1), as demais médias, de ambos os clusters, possuem como característica um valor elevado, acima de 50\%. A Tabela 1 apresenta tais variáveis, sendo destacadas aquelas com maiores médias em relação aos clusters gerados, enquanto a Figura 1 apresenta uma comparação entre as médias. 
Tabela 1: Comparação das médias das variáveis entre os clusters.

\begin{tabular}{|l|c|c|c|}
\hline \multicolumn{1}{|c|}{ Variáveis } & Intervalos & \multicolumn{2}{c|}{ Médias } \\
\cline { 3 - 4 } & utilizados & Cluster1 & Cluster 2 \\
\hline O índice semântico. & 0,0 a 1,0 & 0,713 & 0,711 \\
\hline O trabalho do catador é um trabalho como outro qualquer. & 1 a 4 & 2,846 & 2,476 \\
\hline O trabalho do catador é um trabalho sem utilidade social. & 1 a 4 & 2,410 & 3,705 \\
\hline Você conhece pessoalmente algum catador? & 1 a 2 & 1,590 & 1,238 \\
\hline $\begin{array}{l}\text { Em sua opinião o que é mais importante para melhorar a } \\
\text { qualidade de vida do catador. }\end{array}$ & 1 a 2 & 1,872 & 1,857 \\
\hline $\begin{array}{l}\text { Em sua opinião o que é mais importante para ajudar o } \\
\text { catador. }\end{array}$ & 1 a 2 & 1,436 & 1,981 \\
\hline Lidar com os resíduos (lixo) no dia-a-dia é um trabalho.... & 1 a 2 & 1,615 & 1,752 \\
\hline O resíduo (lixo) é uma fonte de renda? & 1 a 4 & 2,641 & 2,990 \\
\hline $\begin{array}{l}\text { Separar o resíduo (lixo) em casa significa: não misturar os } \\
\text { materiais secos junto com os orgânicos e rejeitos. }\end{array}$ & 1 a 4 & 3,103 & 3,819 \\
\hline $\begin{array}{l}\text { Em sua opinião o aumento da produção de resíduo (lixo) no } \\
\text { mundo é devido principalmente. }\end{array}$ & 1 a 2 & 1,590 & 1,676 \\
\hline O resíduo (lixo) que é produzido na cidade possui. & 1 a 3 & 2,333 & 2,410 \\
\hline
\end{tabular}

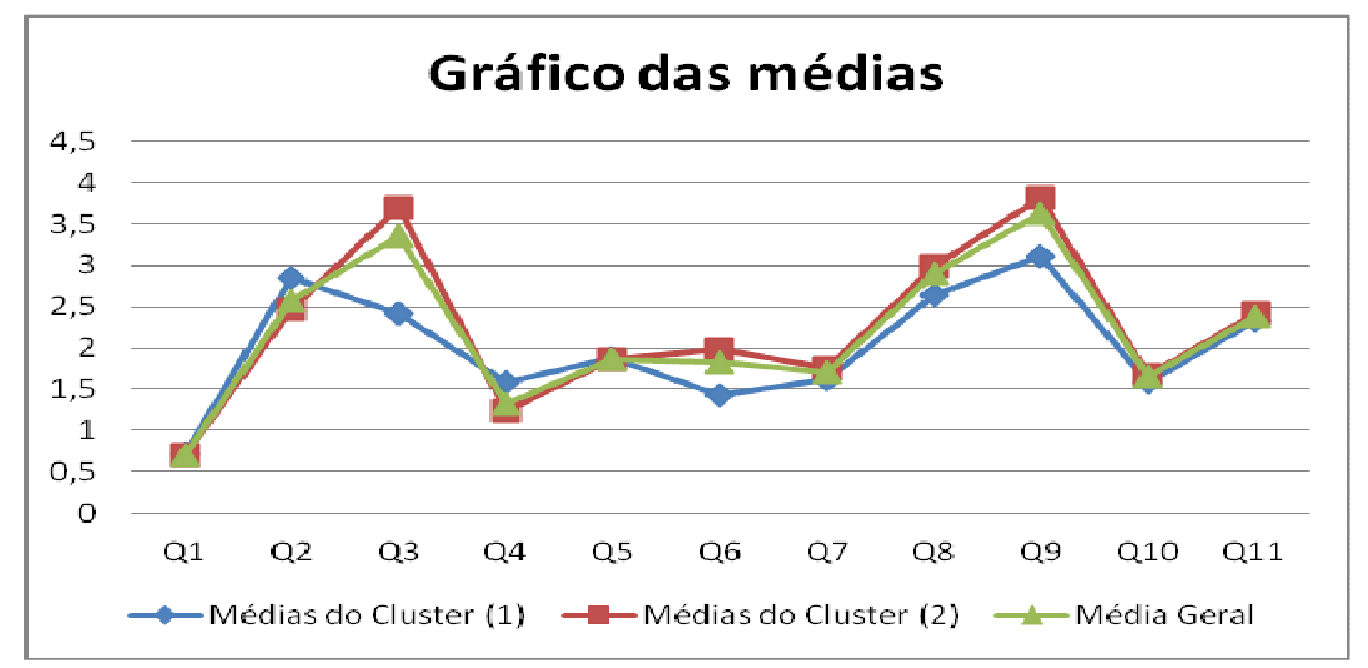

Figura 1: Comparação entre as médias

A partir deste fato e na busca de uma análise mais aprofundada, optou-se por aplicar o método estatístico de análise discriminante, pois este permite uma avaliação mais cuidadosa das variáveis que mais discriminam os 144 casos distribuídos nos dois clusters. Sendo assim, a análise discriminante stepwise apontou 5 variáveis de forma estatisticamente significativa. Vale ressaltar que devido ao fato da variável "ano escolar" (discriminada no passo 5) corresponder a uma variável descritiva, optou-se neste trabalho por não considera-la nas análises subsequentes. Além disso, outro fato merecedor de destaque é que este modelo apresentou uma correlação canônica equivalente a 0,848 , o que indica que $71,9 \%$ da variância da discriminação dos casos válidos podem ser explicadas por estas cinco variáveis. 
Os resultados referentes à classificação dos resultados proveniente da análise discriminante apresentam que $95,1 \%$ dos casos originais foram agrupados corretamente, sendo que o cluster (1) apresentou 92,3\% de casos corretos e o cluster (2) apresentou correção de $96,2 \%$ dos casos. A partir da aplicação do método pôde-se evidenciar que três das variáveis consideradas apresentam maiores médias para o cluster (2), conforme descreve a Tabela 2, enquanto a Figura 2 apresenta uma comparação entre as médias.

Tabela 2: Comparação das médias das variáveis discriminadas menos o ano escolar.

\begin{tabular}{|c|c|c|c|}
\hline \multirow[b]{2}{*}{ Variáveis discriminadas } & \multirow[b]{2}{*}{$\begin{array}{l}\text { Intervalos } \\
\text { utilizados }\end{array}$} & \multicolumn{2}{|c|}{ Médias } \\
\hline & & Cluster1 & Cluster 2 \\
\hline $\begin{array}{l}\text { 1- Em sua opinião o que é mais importante para ajudar o } \\
\text { catador. }\end{array}$ & 1 a 2 & 1,436 & 1,981 \\
\hline 2- O trabalho do catador é um trabalho sem utilidade social. & 1 a 4 & 2,410 & 3,705 \\
\hline $\begin{array}{l}\text { 3- Separar o resíduo (lixo) em casa significa: não misturar os } \\
\text { materiais secos junto com os orgânicos e rejeitos. }\end{array}$ & 1 a 4 & 3,103 & 3,819 \\
\hline 4- Você conhece pessoalmente algum catador? & $1 \mathrm{a} 2$ & 1,590 & 1,238 \\
\hline
\end{tabular}

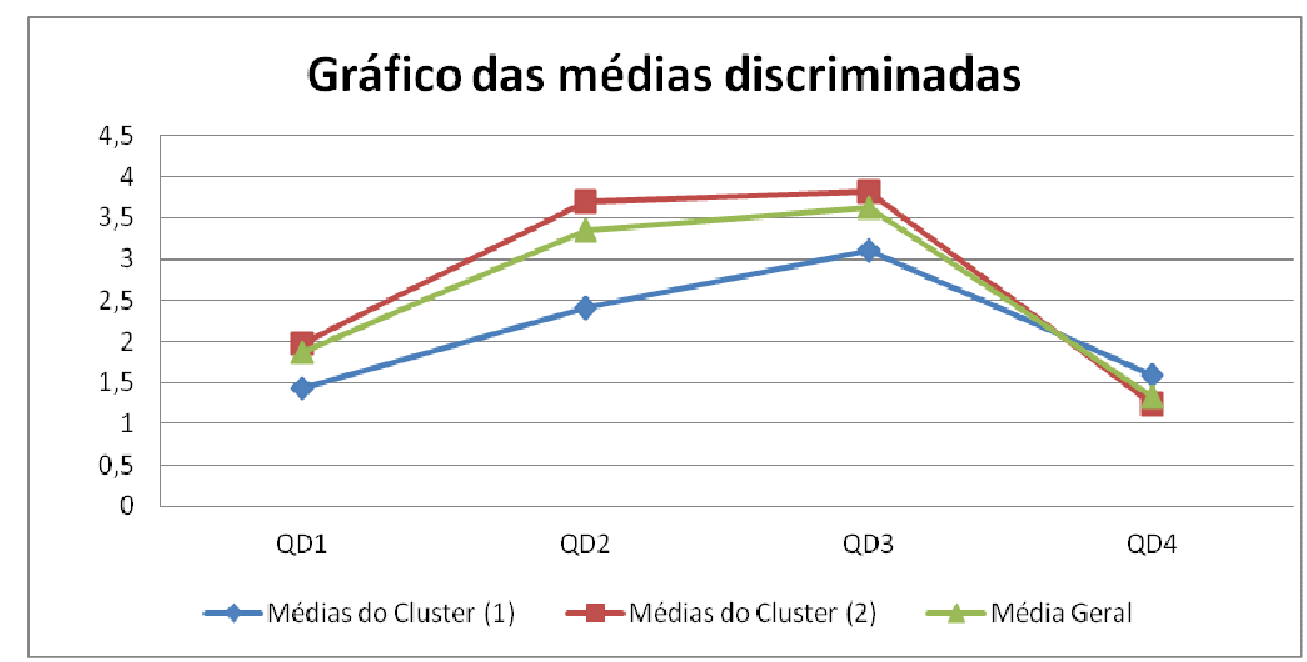

Figura 2: comparação entre as médias discriminadas.

É importante destacar aqui que das quatro variáveis discriminantes a $1 \underline{a}$, $2^{\underline{a}}$ e $4^{\underline{a}}$ estão relacionadas à semântica do trabalho, enquanto a $3^{\underline{a}}$ relaciona-se com a semântica do material. As análises dos resultados iniciam-se por meio da variável que se encontra relacionada à semântica do trabalho, correspondente a seguinte questão: "Em sua opinião, o que é mais importante para ajudar o catador?". As respostas possíveis foram: "1- Doar uma cesta básica mensalmente" e "2- Separar o resíduo (lixo) diariamente", onde a primeira está relacionada à semântica negativa e a segunda à semântica positiva. Os resultaram apontaram que das 24 respostas que atribuem a 
doação de uma cesta básica mensalmente como sendo a melhor forma de ajudar o catador, 91,7\% destes casos compõem o cluster (1) ao passo que $85,8 \%$ dos 120 casos que atribuem a separação do resíduo diariamente se configurar como a melhor forma de ajudar o catador encontram-se no cluster (2).

A segunda variável discriminante está descrita por meio da seguinte afirmação: "O trabalho do catador é um trabalho sem utilidade social". As respostas possíveis são: 1- Concordo plenamente, 2- Concordo parcialmente, 3- Discordo parcialmente e 4- Discordo plenamente. Salienta-se que quanto maior o número da resposta maior sua relação com a semântica positiva e vice-versa. Os resultados gerados apontam que no cluster (1) a opinião quanto à utilidade social do catador está mais dispersa entre as quatro possibilidades de resposta em comparação ao cluster (2), onde há uma concentração na ordem de $80,0 \%$ dos casos na resposta 4 , ou seja, discorda plenamente com a afirmação que diz ser o trabalho do catador um trabalho sem utilizada social.

A terceira variável discriminante relaciona-se, conforma acenado anteriormente, com a dimensão do material (resíduo sólido), e como na questão anterior, balizou-se por meio de uma afirmação: "Separar o resíduo (lixo) em casa significa: não misturar os materiais secos junto com os orgânicos e rejeitos". Este cabeçalho tinha como respostas possíveis: 1- Discordo plenamente, 2- Discordo parcialmente, 3- Concordo parcialmente e 4Concordo plenamente. O modelo aponta que $100 \%$ dos casos relacionados ao cluster 2 concordam, seja parcialmente ou plenamente, enquanto que os casos do cluster 1 apresentam dispersão entre as quatro respostas possíveis, porém $76,9 \%$ dos casos também concordam com a afirmação, seja parcialmente ou plenamente.

A quarta variável foi a única que pela análise discriminante a média do cluster (1) superou a do cluster (2). A questão que retrata está variável foi: "Você conhece pessoalmente algum catador?" E as respostas possíveis foram: 1- Não e 2- Sim. Apesar de $66,7 \%$ dos casos envolvendo ambos os clusters terem afirmado não conhecer nenhum catador, pode-se observar que $59 \%$ dos casos do cluster (1) dizem conhecer algum catador, ao passo que no cluster (2) essa porcentagem é de apenas $23,8 \%$.

Estas análises realizadas a partir dos clusters e discriminante reforçam a questão de que o cluster (2) tende a uma semântica positiva, no entanto, não é correto atribuir o inverso ao cluster (1), requerendo para isso um maior aprofundamento junto aos estudantes, a partir de pesquisas qualitativas cujos resultados podem trazer maiores elementos para a análise por meio da triangulação com os dados deste trabalho. No tópico a seguir apresentam-se as conclusões e análises derivadas do referencial adotado, da vivência dos pesquisadores e dos dados estabelecidos por meio das técnicas estatísticas, buscando evidenciar, inclusive, sobre a não precipitação em adequar o cluster (1) a semântica negativa. 


\section{Conclusões}

O referencial adotado neste trabalho narra sobre a necessidade de atribuir significados positivos à atividade do catador e ao material reciclável para uma maior compreensão voltada para os aspectos sociais, econômicos e ambientais que há no trato dos resíduos sólidos. A literatura aponta que estes aspectos devem estar correlacionados a uma semântica positiva, advinda de percepções sociais cujo resultado tende a levar a uma maior valoração social do catador, influenciando em sua própria imagem e naquilo que eles próprios devem identificar como positivo em suas ações. Este discurso e semântica positivos vêm ao encontro das prerrogativas legais que abordam sobre a gestão de resíduos sólidos, sendo estas a base de ação dos Estados e Municípios.

A partir deste trabalho, pôde-se evidenciar que os alunos de $6^{\circ}$ e $7^{\circ}$ ano da Escola Municipal Álvaro Botelho, que se encontram inseridos num trabalho de extensão universitário, em sua maioria, tendem a uma semântica positiva em relação aos temas tratados. Portanto, os resultados preliminares das ações de extensão podem ser apontados como satisfatórios, pois os estudantes estão absorvendo os conceitos normativos relacionados à gestão dos resíduos sólidos.

No entanto, um aspecto chama a atenção. A grande maioria dos estudantes desconhece um catador, sendo que o cluster (1), cujo resultado estatístico aponta para uma menor aproximação à semântica positiva, configura-se como aquele que mais apresenta estudantes que conhecem um catador e, por consequência, pode-se depreender que também conhecem suas dificuldades, necessidades e atuação. Desta forma, entende-se que o discurso preconizado pelo cluster (1) se configura mais crítico que o discurso preconizado pelo Cluster (2), cuja maior sintonia com o discurso normativo reflete mais uma ingenuidade bem intencionada do que um posicionamento proativo sobre a questão.

Esta criticidade em relação ao discurso normativo pode se configurar como a base para as novas ações de extensão, onde deve-se buscar reconhecer a realidade (do catador, da escolar, do bairro e do município) e sobre as dificuldades acima narradas, a fim de problematizar o discurso normativo (advindo de aspectos legais) e as demandas para que este se concretize. Ou seja, não basta simplesmente reproduzir o discurso, mas sim, conhecer a realidade e interpretá-la com o intuito de ampliar a percepção entre o hiato que há no tocante a realidade daqueles que estão no dia-a-dia da atividade de catação e daquilo que se vislumbra como positividade discursiva e semântica. Esta proposta, advindas das análises estabelecidas considerando a leitura prática dos autores, bibliografias sobre a temática e os dados gerados, não tende a levar a uma noção negativa sobre o catador e ao resíduo sólido, mas apresentar aos estudantes o árduo trabalho desenvolvido frente às demandas necessárias para que se avancem os trabalhos de reciclagem no município, onde tanto o poder público como a sociedade pode colaborar de forma significativa, na busca do que se estabelece na base legal. Assim, Revbea, São Paulo, V.9, № 2: 270-286, 2014. 
vislumbra-se que a busca pela semântica positiva que esteja atrelada ao trabalho do catador e aos materiais recicláveis se faça de forma crítica e contemporizada.

Ou seja, apesar da importância da separação dos resíduos, da urgência em se pensar num desenvolvimento que preze aspectos ambientais, o valor econômico do "lixo", a importância social do catador (que ainda depara-se com diversas dificuldades para que sua atuação seja valorizada socialmente de forma efetiva), e a necessidade de sua organização. Desta forma, sugere-se que nessa nova etapa do trabalho de extensão, se estabeleçam intercâmbios, num primeiro momento, envolvendo os alunos e os catadores, estejam eles organizados em associações/ cooperativas ou não, expandindo este intercâmbio para a comunidade escolar (pais, professores, vizinhança). Este intercâmbio deve balizar as ações no âmbito escolar envolvendo inclusive, atores governamentais para que se estabeleça uma educação ambiental problematizadora, seja no tocante aos aspectos práticos (envolvendo a separação dos materiais recicláveis, por exemplo), seja nos aspectos políticos com vistas a uma maior efetividade no que tange a cidadania.

Por fim, deve-se ressaltar que trabalho semelhante ao aqui proposto deve ser expandido e aperfeiçoado a fim de trazer elementos para maior efetividade nas ações de extensão universitária. Neste esforço, vale elucidar que pesquisas qualitativas podem ser realizadas, cujos resultados devem ser somados e triangulados com pesquisas quantitativas, a fim de estabelecer uma maior robustez às análises em questão.

\section{Referências}

AAKER, D.A.; KUMAR,V.; DAY, G.S. Pesquisa de marketing. São Paulo: Atlas, 2001.

BRASIL. Presidência da República/Casa Civil. Política Nacional de Resíduos Sólidos. Lei no 12.305, de 02 de agosto de 2010. Disponível em: <http://www.planalto.gov.br/ccivil 03/ ato2007-2010/2010/lei//12305.htm>.

Acesso em 02/07/11.

CARMO, M.S.; OLIVEIRA, J.A.P.; MIGUELES, C.P. Significado do Lixo e Ação Econômica - a Semântica do Lixo e o Trabalho dos Catadores do Rio de Janeiro. XXVIII encontro da ANPAD, Curitiba, Setembro, 2004.

CARMO, M.S.; SCARLET, M. A Semântica 'Negativa' do Lixo como Fator 'Positivo' à Sobrevivência da Catação - Estudo de Caso sobre a Associação dos Recicladores do Rio de Janeiro. Anais do XXIX Encontro da ANPAD. Brasília, 2005.

CARMO, M.S.; SCARLET, M.; OLIVEIRA, J.A.P.; ARRUDA, R.G.L. O Trabalho com Resíduos pelos Classificadores - o Papel da Semântica do Lixo no Reconhecimento Social e Identidade Profissional. Anais do XXX Encontro da ANPAD. Salvador, Setembro, 2006. 
CARMO, M.S.; SCARLET, M. A Problematização do Lixo e a Produção do Reciclável - uma analítica da gestão de resíduo pós-consumo e seus efeitos em Consumidores/Geradores e Catadores. Anais do XXXIII Encontro da ANPAD. São Paulo, Setembro, 2009.

FOSSÁ, M.I.T. As Representações Sociais Construídas pelos Catadores de Materiais Recicláveis. Anais do XXX Encontro da ANPAD. Salvador, Setembro, 2006.

MALHOTRA, N.K. Pesquisa de marketing: uma orientação aplicada. Porto Alegre: Bookman, 2006.

OLIVEIRA, L.C. Do Coletar ao Reciclar: Ação coletiva para a separação dos resíduos sólidos. Projeto FAPEMIG SHA-APQ-01910-08. Incubadora Tecnológica de Cooperativas Populares/UFLA, Lavras, 2010.

PHILLIPS, N.; SEWELL, G.; JAYNES, S. Applying Critical Discourse Analysis Strategic Management Research. Organizational Research Methods. Jan/2008.

QUIVY, R; CAMPENHOUDT, L.V. Manual de investigação em ciências sociais. Lisboa: Gradiva, 1992.

SPINK, M.J.; FREZZA, R.M. Práticas discursivas e produção de sentidos: a perspectiva da psicologia social. In: SPINK, M.J. (org.). Práticas discursivas e produção de sentidos no cotidiano: aproximações teóricas e metodológicas. (Cap. I. pp. 17-40) 3ª Ed. São Paulo: Cortez, 2004.

SPINK, M.J.; MEDRADO, B. Produção de sentidos no cotidiano: uma abordagem teórico-metodológica para análise das práticas discursivas. In: SPINK, M.J. (org.). Práticas discursivas e produção de sentidos no cotidiano: aproximações teóricas e metodológicas. (Cap. II. PP. 41-62) 3를 Ed. São Paulo: Cortez, 2004.

SPINK, M.J.; LIMA H. Rigor e visibilidade: a explicitação dos passos da interpretação. In: SPINK, M.J. (org.). Práticas discursivas e produção de sentidos no cotidiano: aproximações teóricas e metodológicas. (Cap. IV. pp. 93-122) 3a Ed. São Paulo: Cortez, 2004.

STUBBE, M.; LANE, C.; HILDER, J.; VINE, E.; VINE, B.; MARRA, M.; HOLMES, J.; WEATHERALL, A.. Multiple discourse analyses of a workplace interaction. Discourse Studies, vol. 5, no. 3, August 2003, pp. 351-388. 